\title{
Aggregation of Fine Particles at the Sediment-Water Interface
}

\author{
Ketth D. Stolzengach, ${ }^{1}$ Kathleen A. Newman, and Charles S. Wong ${ }^{2}$
}

Parsons Laboratory, Department of Civil Engineering, Massachusetts Institute of Technology, Cambridge

\begin{abstract}
The presence of a bottom sediment layer agitated by mechanical stirring or by resident organisma (tubificid oligochaetes) significantly increases the rate at which fine $(1 \mu \mathrm{m})$ cohesive particles are removed from suspension in laboratory columns. Measured rates of particle removal are equivalent to deposition velocities ranging from $0.23 \mathrm{~m} \mathrm{day}^{-1}$ to $0.41 \mathrm{~m} \mathrm{day}^{-1}$. These rates are an order of magnitude faster than deposition by gravitational settling or coagulation with larger particles in the water column as observed in experimental controls. It is hypothesized that the increased removal rate is the result of aggregation in a sediment layer at the bed-water interface characterized by loosely bound (fluffy), porous material hydrodynamically coupled to the water column. According to this hypothesis particle removal occurs when motion of the overlying water or organism activity causes suspended fine particles to collide with and stick to the interfacial sediment. This new hypothesis is supported by the mass and size distribution of tracer particles recovered in cores and sediment traps at a coastal site and by theoretical estimates of interfacial aggregation rates.
\end{abstract}

\section{INTRODUCTION}

A significant fraction of the total mass of suspended material in natural water bodies is composed of particles smaller than $10 \mu \mathrm{m}$ [Lal and Lerman, 1975; McCave, 1975; Clegg and Whitfield, 1990]. The transport of these fine particles is important in the geochemical cycling of natural elements and the fate of anthropogenic contaminants. Of particular significance is the rate at which fine particles are deposited in bottom sediments.

McCave $[1985 a, b]$ concludes that particle settling exceeds other possible deposition modes such as Brownian diffusion through a benthic boundary layer. However, particles smaller than $10 \mu \mathrm{m}$ settle so slowly (less than $1 \mathrm{~m} \mathrm{day}^{-1}$ for marine sediments [McCave, 1984], cells [Smayda, 1970], and sewage [Hunt and Pandya, 1984; Wang, 1988]) that in the absence of other deposition mechanisms, they would remain in the water column for weeks to years in lakes and coastal waters and for decades in the deep ocean. For this reason, the dominant process for the deposition of fine particles has been thought to be their incorporation into larger, faster-settling aggregates by coagulation or biogenic repackaging in the water column [Edzwald et al., 1979; McCave, 1984; Hunt and Pandya, 1984; Farley and Morel, 1986; Fowler and Knauer, 1986].

In this article we present laboratory experiments in support of a new hypothesis that fine particles are removed from suspension by aggregation in a hydrodynamically active "fluff" layer at the sediment-water interface. Measured rates of removal by this mechanism are significantly faster than rates of removal by settling of primary particles or by coagulation with larger particles in the water column. We conclude that interfacial aggregation may regulate the deposition of fine particles, particularly in the sub-micron size range.

\footnotetext{
'Now at Civil Engineering Department, University of California, Los Angeles.

${ }^{2}$ Now at Department of Civil and Mineral Engineering, University of Minnesota, Minneapolis.
}

Copyright 1992 by the American Geophysical Union.

Paper number 92JC01827.

0148-0227/92/92JC-01827\$05.00

\section{THE FLUFF LAYER HYPOTHESIS}

In many water bodies the sediment-water interface is characterized by loosely aggregated material of high porosity and low strength compared to underlying, more consolidated sediments. Such "fluff" layers are familiar to those who scuba dive in areas where fine sediments are present and have been described qualitatively by many investigators [Fitzgerald, 1980; Rhoads and Boyer, 1982; Summerhayes et al., 1985]. The development of specialized instruments for sampling the "flocculent layer" [e.g., Bothner and Valentine, 1982; Reimers, 1987] reflects the perceived importance of this interface in geochemical cycling [Lee et al., 1979; Rhoads et al., 1984; Olivarez et al., 1989; Wakeham, 1990; Baker et al., 1991; Beier et al., 1991].

Quantitative in-situ measurements at the sediment-water interface reveal significant gradients of physical and chemical properties in an interfacial layer of thickness ranging from centimeters (see Figure 1) to less than a millimeter [Reimers, 1987; Archer et al., 1989; Gunderson and Jorgensen, 1990; Davison et al., 1991]. Measured sediment porosities at the interface are typically greater than 0.90 and may be as high as 0.99 [Jahnke et al., 1986; Reimers, 1987]. The structure of the interfacial sediment layer may reflect episodic deposition of organic detritus [Billett et al., 1983; Lampitt, 1985; Hecker, 1990], reworking by organisms [Rhoads and Boyer, 1982], or accumulation of fine material in depositional environments [Summerhayes et al., 1985].

Although little is known about the mechanical properties of these surface layers, a solids content of only several percent is theoretically sufficient to establish a three-dimensional matrix of solid-solid connections with a measurable yield strength [Williams and Williams, 1989]. Even more porous dendritic structures formed by deposited fine particles have been observed in granular media [Payatakes and Gradon, 1980] and in simulations of aggregation on surfaces [Witten and Cases, 1986]. When the yield strength is exceeded, the interfacial sediment layer may shear as a viscoelastic material (fluid mud) [Ross and Mehta, 1989].

We hypothesize that fine suspended particles are continually removed from the water by aggregation within the interfacial layer. According to our hypothesis, fine particles are continually 


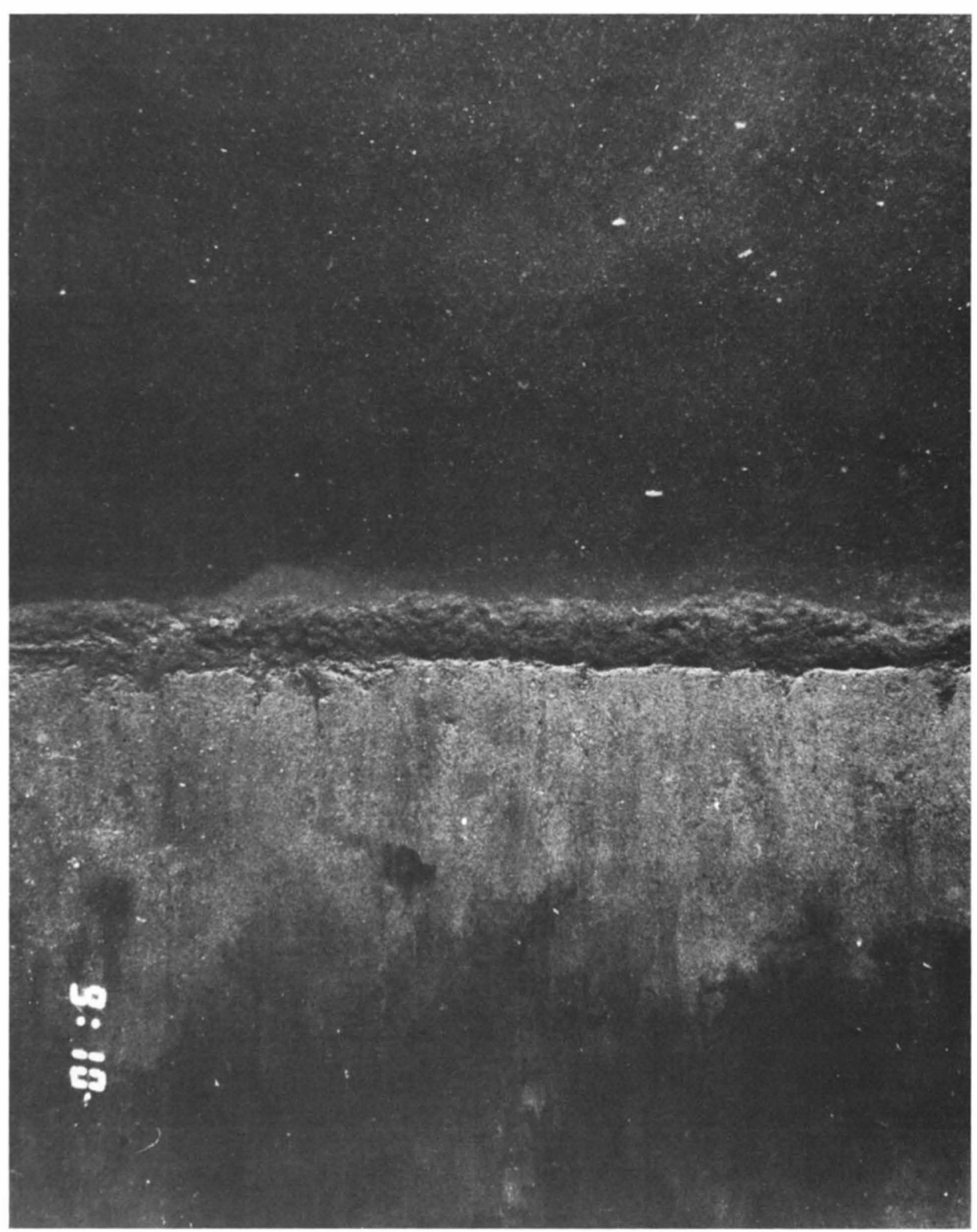

Fig. 1. A porous interfacial "fluff" layer about $1 \mathrm{~cm}$ thick formed from detrital products of the spring plankton bloom in Long Island Sound in March, 1985. Photograph taken using the Remots ${ }^{\star}$ sediment profile camera [Rhoads and Cande, 1971]. (Photo courtesy of D. Rhoads) 


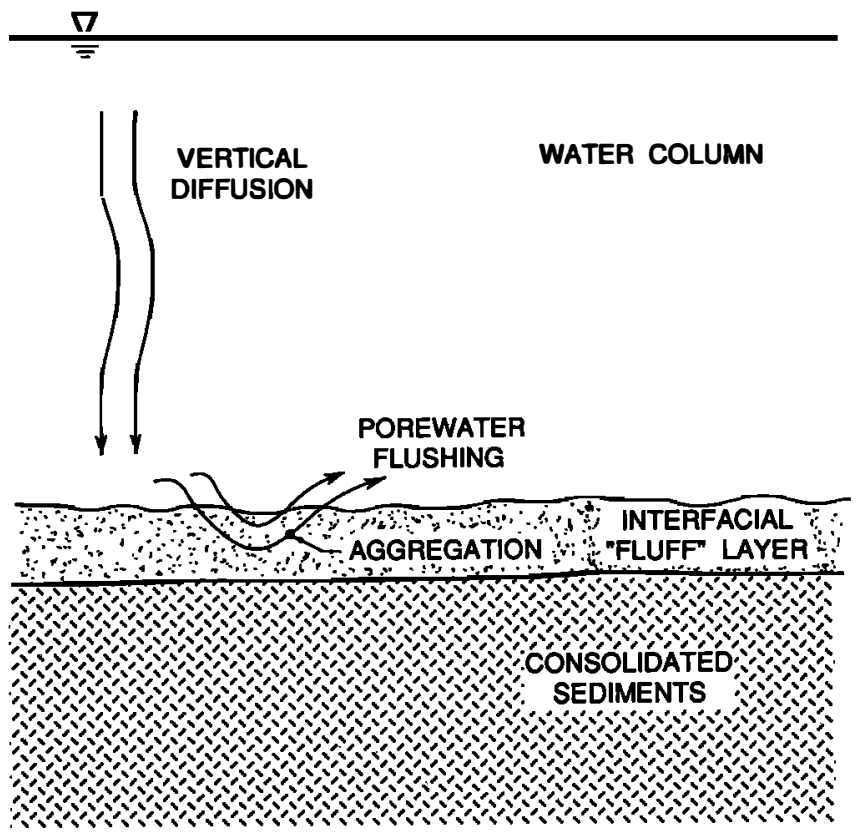

Fig. 2. Hypothesized processes leading to aggregation of fine particles at the sediment-water interface.

transported to the sediment-water interface by vertical turbulent mixing in the water column (see Figure 2). At the interface the fine particles are circulated through the highly porous surface layer by fluid motions induced by near-bottom currents or the activities of benthic organisms. Removal from suspension occurs when a fine particle collides with and sticks to the interfacial material. The matrix of elemental particles and flocs constituting the interfacial sediments can theoretically remove a wide size range of fine particles from suspension by this mechanism [Stolzenbach, 1989]. Fluidization of the interfacial material itself promotes additional exchange of fluid between the water column and the sediments and increases the rate of collisions and effective deposition of fine particles.

\section{EXPEROMENTS}

\section{Materials and Methods}

Fluorescent pigment particles. The fine particles used in our experiments were fluorescent pigment particles obtained in a suspension of Rocket Red fluorescent paint manufactured by the Day Glo Color Corporation, Cleveland, Ohio. The size distribution, settling rates, and coagulation efficiency of these particles have been determined by an earlier study [Newman et al., 1990a]. A stock suspension ( $-5000 \mathrm{ppm})$ of small $(1 \mu \mathrm{m})$, slow-settling $\left(0.017 \mathrm{~m} \mathrm{day}^{-1}\right)$ pigment particles was isolated by decanting a suspension of the original pigment after settling for one day through an 8-cm water column.

Fhy ash interfacial layer. Interfacial layers were created in the bottom of acrylic columns using fly ash obtained from the Public Service Electric and Gas Company, New Jersey. The fly ash was agitated from below by $1-\mathrm{cm}$ Teflon stir bars rotating at approximately $250 \mathrm{rpm}$. The columns were $7 \mathrm{~cm}$ in diameter and $80 \mathrm{~cm}$ tall, fitted with rubber sampling ports at 10-cm intervals. During the experiments the columns were covered with parafilm to prevent evaporation.

Each of five columns was initially filled with $2500 \mathrm{~mL}$ of 0.07- $\mathrm{M} \mathrm{NaCl}$ solution. Four columns (A, B, D, E) were stirred; the fifth (C) was quiescent (see Table 1). Fly ash was added to columns A, D, and E in quantities of $50 \mathrm{~g}, 25 \mathrm{~g}$, and $25 \mathrm{~g}$ respectively. The columns were left 3 days to allow for stabilization of the interfacial layers and clearing of the water columns over the layers. Initial suspended solids concentrations in the supernatants of columns A, D, and E were then measured. The supernatant in column D was carefully siphoned out, the interfacial layer fly ash was removed, and the supernatunt and stir bar were returned to the cleaned column.

The particle removal experiment began with additions of 47-mL aliquots of stock suspension of fluorescent pigment particles to each of the experimental columns to yield initial concentrations of about $50 \mathrm{ppm}$. The stock suspension was added in equal quantities through ports near the bottom, middle, and top of the columns and the water columns were immediately mixed by injection of $50 \mathrm{~mL}$ of air through a port near the bottom but above the interfacial layers. Samples from each column were withdrawn with 5-mL syringes through the bottom, middle, and top ports $15 \mathrm{~min}$ after pigment particle addition and through the middle port at regular intervals thereafter.

TABLE 1. Experimental Conditions and Observed Effective Deposition Velocities for the Fly Ash Interfacial Layer Experiment

\begin{tabular}{cccccc}
\hline Column & Fly Ash, g & Stirred & $\begin{array}{c}\text { Supernatant } \\
\text { Suspended } \\
\text { Solid, ppm }\end{array}$ & $\begin{array}{c}\text { Initial } \\
\text { Depth, cm }\end{array}$ & $\begin{array}{c}\text { Effective } \\
\text { Deposition } \\
\text { Velocity V } \\
\text { m day }^{-1}\end{array}$ \\
\hline C & none & no & nm & 71.6 & 0.019 \\
B & none & yes & nm & 71.5 & 0.017 \\
D & $25 *$ & yes & 6.1 & 70.1 & 0.076 \\
E & 25 & yes & 2.3 & 69.3 & 0.27 \\
A & 50 & yes & 4.6 & 71.6 & 0.23 \\
\hline
\end{tabular}

Here nm stands for not measured; no solids added.

*Removed before addition of pigment particles.

Oligachaete-mediated interfacial layer. Sediment was collected from the Assabet River, Massachusetts, about 1 mile $(1.6 \mathrm{~km})$ downstream from the Westborough Waste Water Treatment Facility in January and stored at room temperature for 2 months before screening through 20 -gauge screen $(840-\mu \mathrm{m}$ openings) to remove existing biota. Screened wet sediment $\left(200 \mathrm{~cm}^{3}\right)$ was added to each of five 1-L glass beakers (cross-sectional area $56 \mathrm{~cm}^{2}$ ) and distilled water was added to bring the total volume to $1000 \mathrm{~mL}$ (Table 2). The fluid in the beakers was stirred at $8 \mathrm{rpm}$ with a Phipps and Bend six-paddle stirrer for 2 days before the addition to beakers 4,5 , and 6 of tubificid oligochaetes purchased from Tropic Isle Aquarium, Framingham, Massachusetts. One-gram additions ( $\sim 510$ individuals) resulted in population densities of about nine oligochaetes per square centimeter of sediment.

Three weeks with stirring were allowed for colony stabilization before the supernatant was analyzed for suspended solids

TABLE 2. Experimental Conditions and Observed Effective Deposition Velocities for the OligochaeteMediated Interfacial Layer Experiment

\begin{tabular}{ccccccc}
\hline & $\begin{array}{c}\text { Approximate } \\
\text { Population } \\
\text { Added }\end{array}$ & $\begin{array}{c}\text { Population } \\
\text { Counted at } \\
\text { End }\end{array}$ & $\begin{array}{c}\text { Suspended Solids } \\
\text { Concentration } \\
\text { before Addition } \\
\text { of Pigment, ppm }\end{array}$ & $\begin{array}{c}\text { Initial } \\
\text { Depth, } \\
\text { cm }\end{array}$ & $\begin{array}{c}\text { Effective } \\
\text { Deposition } \\
\text { Velocity } V_{\text {I }} \text {, } \\
\text { m day }\end{array}$ \\
\hline 2 & 0 & nc & nd & 12.0 & 0.074 \\
3 & 0 & nc & nd & 12.2 & 0.060 \\
4 & 510 & 451 & 14 & 12.0 & 0.29 \\
5 & 510 & 443 & 8 & 12.2 & 0.39 \\
6 & 510 & nc & 5 & 12.0 & 0.41 \\
\hline
\end{tabular}

Here nc stands for not counted; nd, not detectable. 
concentrations and the pigment particle removal experiment was initiated. The colonies of Tubificidae were fed with bread crumbs twice; the second feeding occurred the day before the experiment was begun.

The particle removal experiment began with addition of 2-mL aliquots of stock suspension of fluorescent pigment particles to each of the experimental beakers to yield initial concentrations of about $13 \mathrm{ppm}$. Samples were withdrawn from the middle of the beakers immediately and at regular time intervals thereafter using a glass pipette. Because the loss of pigment particles from the beakers with oligochaete colonies was visibly much more rapid than anticipated, a second addition of pigment particles was made on the second day of the experiments and subsequently those beakers were sampled more frequently.

Upon completion of the experiment the populations in two of the three oligochaete colonies were enumerated by sieving away the sediment and counting all the individuals in the colony as they were removed from the screen with a Pasteur pipette. About $90 \%$ of the oligochaetes added were recovered; most of the oligochaetes recovered were between 2 and $3 \mathrm{~cm}$ long.

Suspended particle analysis. Concentrations of pigment particles in suspension were measured by fluorometry using a Turner 111 fluorometer (Tumer Designs, Sunnyvale, Califomia) with a $350-\mathrm{nm}$ to $480-\mathrm{nm}$ excitation filter and a narrow-band 575- $\mathrm{nm}$ to 600 -nm emission filter. Fluorescence samples were stored in $7-\mathrm{mL}$ glass vials and analyzed upon completion of an experiment. Immediately prior to analysis a $0.01-\mathrm{mL}$ aliquot of a $\mathbf{0 . 5 \%}$ solution of surfactant (Kodak Photoflow 500) was added to each sample vial and the vials were sonicated in an ultrasonic bath and shaken vigorously to resuspend the pigment particles.

Total suspended solids concentrations were measured gravimetrically after evaporation at $105^{\circ} \mathrm{C}$. Supernatant samples (20-40 mL) were withdrawn from the experimental vessel by syringe and filtered through predried, preweighed $47-\mathrm{mm} 0.4-\mu \mathrm{m}$ Nucleopore filters using a glass-fitted Millipore filter holder. Each filter was rinsed with two $10-\mathrm{mL}$ to $15-\mathrm{mL}$ aliquots of distilled water and dried ovemight at $105^{\circ} \mathrm{C}$. The mass of supernatant filtered was determined by weighing the syringe before and after transfer of the sample to the filter.

\section{Results}

Effective deposition velocity. It is use ful to consider the removal of fine particles from the water column in terms of an effective deposition velocity, $V_{I}$, defined by

$$
\dot{N}_{\mathrm{I}}=V_{\mathrm{l}} N_{\mathrm{p}}
$$

where $\dot{N}_{\mathrm{I}}$ is the number of particles deposited per unit area per time and $N_{p}$ is the number concentration (number/volume) of suspended fine particles at the sediment-water interface. It should be noted that $V_{I}$ is not a true velocity but rather a convenient parameter with which to compare deposition by different processes.

In a well-mixed water column the decrease in the suspended particle concentration is given by

$$
N_{\mathrm{p}}(t) / N_{\mathrm{po}}=\exp \left(-V_{\mathrm{I}} t / H\right)
$$

where $N_{\text {po }}$ is the initial concentration of fine particles in suspension, $H$ is the depth of the water column, and $V_{I}$ is assumed to be constant. This expression will be used to interpret our observations of particle removal in laboratory columns.

Fly ash interfacial layer. Fly ash particles settled to the bottom of the column within a day after addition. The resuling layer of fly ash at the bottom of the column remained fluidized and partially suspended by the rotating stir bar. The larger fly ash particles formed a rotating mass at the base of the column, while the finer particles swirled about in a fluidized layer which extended $2 \mathrm{~cm}$ up the column at high concentration and tapered off to part-per-million concentrations over the next centimeter. The fluidized layer undulated and rotated slowly in the same direction as the stir bar but at a much slower rate. Suspended solids concentrations measured at the middle of the columns before addition of pigment particles ranged from 2 to $6 \mathrm{ppm}$ (Table 1).

After addition of the pigment particles and air bubble mixing, the pigment particle concentration was constant over depth in all the columns. After $\mathbf{4 3}$ hours the columns without interfacial layers were still uniform, while the columns with interfacial layers had slight gradients with fluorescence decreasing less than $10 \%$ from top to bottom. The mid-depth fluorescence decreased over time in all the columns, diminishing most rapidly in the columns with fly ash interfacial layers at the bottom, more slowly in the column with the interfacial layer supernatant, and least rapidly in the columns with no fly ash (Figure 3). We infer from the similarity of columns $B$ and $\mathbf{C}$ that stirring did not influence deposition in these columns or in the column with the supernatant only (D).

The fluorescence data from the fly ash column experiments are fit well by exponential functions (Figure 3). The effective deposition velocities calculated from the loss rates using equation (2) range from $0.017 \mathrm{~m} \mathrm{day}^{-1}$ for the columns with no fly ash to about $0.27 \mathrm{~m} \mathrm{day}^{-1}$ for the columns with active interfacial layers (Table 1). The column initially containing only suspended fly ash particles had an effective deposition velocity intermediate between the columns without fly ash and those with fly ash interfacial layers.

Oligochaete-mediated interfacial layer. The tubificid oligochaetes adapted well to the laboratory beakers. Waving tails were generally visible, extending as much as $0.7 \mathrm{~cm}$ above the

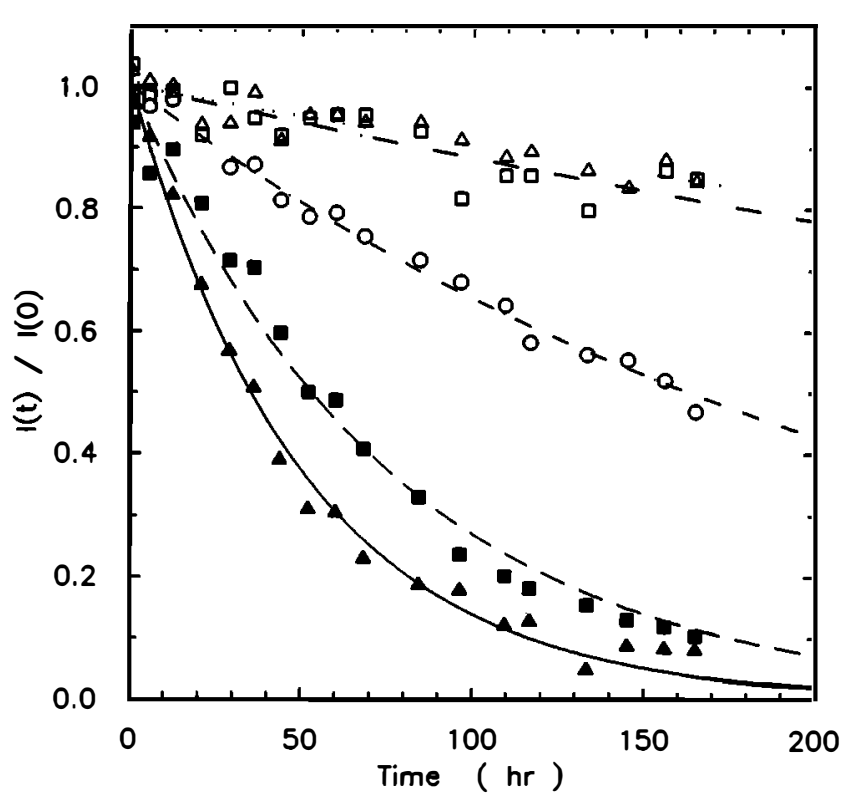

F1g. 3. Decrease in normalized fluorescence intensity over time in columns with no fly ash, B ( $\Delta$ ) and C (ㅁ); in columns with suspended fly ash, D $(0)$; and in columns with agitated fly ash layers, E ( $\Delta)$ and $A(\omega)$. Data are normalized by initial value from exponential nonlinear least squares fit shown by the lines passing through the data. 
sediment in the days following feeding. The activity in the three colonies varied during the stabilization period. When the first pigment was added, the oligochaetes in beaker 4 extended about $0.65 \mathrm{~cm}$ above the sediment, compared with about $0.3 \mathrm{~cm}$ for those in beakers 5 and 6 . The oligochaetes in beaker 4 were generally the most evenly distributed and those in beaker 6 tended more toward patchy colonization of the surface. Concentrations of suspended solids measured in the beakers with worms before addition of pigment particles ranged from 5 to $14 \mathrm{ppm}$ (Table 2).

After colonization the sediment became extensively worked by the tubificid oligochaetes. At the end of the experiment the upper $2 \mathrm{~cm}$ of sediment was very loose and fluffy, jiggling in a gel-like fashion when the beakers were shifted and readily resuspending when the overlying water was stirred vigorously.

Concentrations of suspended pigment particles were vertically uniform throughout the experiment as a result of mixing by the stirring paddles. After the first addition of pigment particles the fluorescence in the beakers with oligochaetes was inadequately monitored as it diminished to background levels during the first 22 hours; for this reason we consider the experiments in those beakers to begin with the second addition of pigment particles. Fluorescence decreased over time in all beakers, with the decrease being most rapid in the beakers with oligochaetes (Figure 4).

The fluorescencedata from the oligochaete experiments are also fit well by exponential functions that decrease to a nonzero background level (Figure 4). The background fluorescence, presumably from fluorescent components occurring naturally in the sediment, was not measured independently and so was determined by the fit to the data from the beakers without oligochaetes. The effective deposition velocities calculated from the loss rates using equation (2) range from $0.060 \mathrm{~m} \mathrm{day}^{-1}$ for the beakers without oligochaetes to $0.41 \mathrm{~m} \mathrm{day}^{-1}$ for the beakers with tubificid oligochaetes (Table 2).

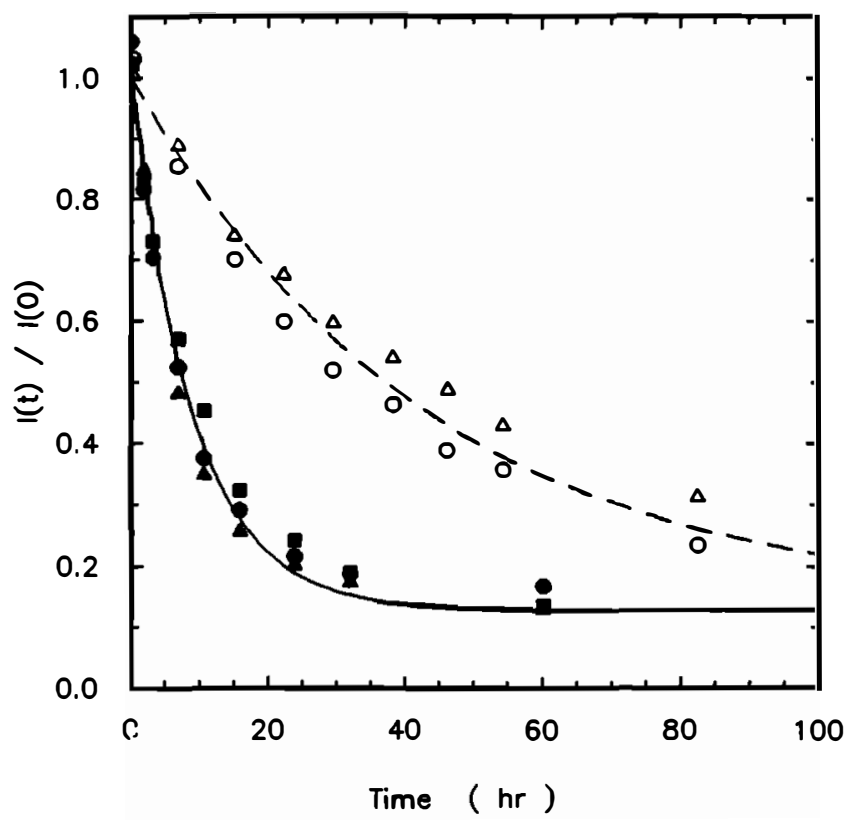

Fig. 4. Decrease in nornalized fuorescence intensity over time in beakers with sieved sediment only, beaker $2(\square)$ and $3(\Delta)$; and in beakers with sieved sediment and tubificid oligochaetes, beakers $4(\nabla), 5(\Delta)$, and $6(\bullet)$. Data are normalized by initial value from exponential nonlinear least squares fit shown by the lines passing through the data.

\section{Discussion}

\section{Experiments}

It is clear from the results of both experiments that the presence of an agitated interfacial sediment layer increases the rate at which fine particles are removed from the water column. Observed deposition rates (between 0.23 and $0.41 \mathrm{~m} \mathrm{day}^{-1}$ ) are significantly faster than removal by pure settling or by coagulation with larger particles in experimental controls.

Fly ash interfacial layer. In the columns without fly ash (B and C), the pigment particles appear to settle out at their calculated Stokes settling velocity. This is expected because the pigment particles used in these experiments are known to be very stable with respect to self-coagulation. Although a range of particle sizes can cause apparent second-order loss from the water column [Newman et al., 1990a], deviations from first order are not evident in these data since the pigment particles were presettled to narrow the size distribution and remove the large, fast-settling particles ( $>0.1 \mathrm{~m} \mathrm{day}^{-1}$ ) and because pure settling produces less than $20 \%$ loss from the water column over the course of the experiment.

Augmented particle removal from the column initially containing only suspended fly ash (column D) was probably the result of a combination of coagulation with settling fly ash particles in the water column and aggregation with the small amount of fly ash that settled to the bottom during the course of the experiment. The rate of removal from this column is one fourth of the rate in the columns with substantial fluidized layers in spite of the fact that the total mass of fly ash is 1000 times less.

The difference in removal rate between column $D$ and the columns with a fluidized interfacial layer ( $A$ and $E$ ) must be atributed to an interfacial process, as the water column conditions were similar. We note that the rate at which particles are removed is not necessarily dependent upon the total mass of sediment in the layer. Removal is actually slightly less rapid from column A than from column $\mathrm{E}$ which has half the fly ash. We interpret this result to mean that although the total mass of sediment was greater in one column, about the same amount of fly ash was active as an interfacial layer.

Oligochaete-mediated layer. It is significant that even in the beakers without oligochaetes the effective deposition velocity is 4 times the fine-particle settling velocity observed in the fly ash experiment control columns (B, C). The gentle stirring did not produce any observable disturbance of the surficial sediments, and the suspended solids concentration in the supernatant was low. Since calculated rates of water column coagulation [Farley and Morel, 1986] are much too slow to account for the observed deposition, we conclude that aggregation and subsequent removal of the fine particles must have been caused by induced flow through the interfacial material and subsequent filtration of the Gine particles.

When tubificid oligochaetes are present, the dominant mechanism of interfacial aggregation is probably the agitation of the interfacial sediments resulting from the waving of the oligochaete cails. Ingestion of particles is not likely, as the oligochaetes feed with their heads buried in the sediments [Fisher et al. , 1980]. Simple calculations indicate that coagulation of fine particles with ejected fecal pellets is also negligible. We are unable to evaluate to what extent the increased paricle removal in the presence of the oligochaetes may be the result of oligochaete-induced changes in the efficiency of coagulation between fine particles and the sediments. 


\section{Other Studies}

Salem Sound. Aggregation in an interfacial layer may explain the mass of tracer particles deposited in bottom sediments during a field study in Salem Sound, Massachusetts [Newman et al., $1990 b$ ]. This study used flow cytometry to both identify and size individual particles of the Rocket Red fluorescent pigment. Flowcytometric analysis of sediment cores indicated that a minimum of 7\% of the tracer mass reached the sediment in the sound within 8 days after being introduced through a sewage outfall. However, the field samples contained significantly more of the smallest tracer particles (down to about $0.5 \mu \mathrm{m}$ in radius) than could be explained the basis of settling rates measured in the laboratory [Newman et al., 1990a]. In fact, measured size distributions of tracer particles in bottom sediments were essentially identical to that of the initial stock of pigment particles. Aggregation of the tracer with faster settling particles in the water column was ruled out because the concentration of suspended coagulant particles and the fluid shear were not sufficient to effect the observed deposition given the small coagulation efficiency of the tracer particles [Newman et al., 1990b]. These findings provide significant support for the existence of an alternative deposition mode involving particle aggregation at the sediment-water interface and demonstrate that even extremely fine submicron particles can be deposited efficiently by this mechanism.

An estimate of the effective deposition rate $V_{I}$ in Salem Sound can be derived assuming that the tracer particles were removed from the water column by deposition in the bottom sediments and by tidal flushing. If the tidal flushing is also modeled as a firstorder process, the fraction of the original mass of tracer deposited in the Salem Sound sediments is $\left[1-\exp \left\{-\left(V_{1} / H+k_{\mathrm{f}}\right) t\right\}\right]$ / [ $\left.1+k_{\mathrm{f}} H / V_{\mathrm{I}}\right]$ where $k_{\mathrm{f}}$ is the first-order tidal flushing rate. Using a value of $k_{\mathrm{f}}=0.2$ day $^{-1}$ and $H=10 \mathrm{~m}$ (based on tidal volumes [Newman et al., 1990b]), we calculate from the observed 7\% deposition after 8 days that $V_{I}=0.26 \mathrm{~m} \mathrm{day}^{-1}$.

This rate of fine particle deposition is consistent with our fly ash experiments. Scuba divers collecting cores in Salem Sound observed a mobile interfacial layer of the order of $1 \mathrm{~cm}$ deep being sheared by long-wave swells. Considering the relatively low collision efficiency of the racer particles $\left(\alpha=5 \times 10^{-4}\right)$ [Newman et al., 1990a], we conclude that effective deposition velocities for natural fine particles with higher collision efficiencies $\left(\alpha=10^{-2}\right.$ to $\left.10^{-1}\right)$ could be at least an order of magnitude higher, i.e., 1 to $10 \mathrm{~m}^{-1 a y}$ at this site.

Interfacial aggregation may also explain why the size distribution of tracer particles accumulated in sediment traps at our study site was also identical to the initial tracer stock [Newman et al., 1990b]. Flow across the open end of a sediment trap is known to create circulation within the trap that may result in fine particles aggregating with settled solids at the trap bottom, thus increasing the trapping efficiency for fine particles [Butman et al., 1986].

MERL Tanks. Santschi et al. [1983] measured the transport of radioactively tagged plastic microspheres from the water column to the sediment in the Marine Ecosystems Research Laboratory (MERL) microcosm tanks. They found that spheres were cleared from the water column at an effective deposition rates as large as $V_{I}=12 \mathrm{~m} \mathrm{day}^{-1}$, which is 100 times their settling velocity ( $0.10 \mathrm{~m} \mathrm{day}^{-1}$ for 3- $\mu \mathrm{m}$ microspheres). They also determined that zooplankton grazing and coagulation with resuspended sediment in the water column contributed negligibly to fine-particle transport and thus concluded that the major mechanism for particle removal must be operative at the bed-water interface.
Because particle transport was much greater during the summer than in winter, they proposed filter feeding by benthic organisms as the dominant process. Our results indicate that shear induced aggregation in an interfacial layer could easily be the cause of the high particle removal rates. Biological reworking could produce a seasonal variability in the transport by regulating the mass of interfacial material actively coupled to the water column.

\section{Theory}

Interfacial aggregation mechanisms. Aggregation of fine particles at the sediment-water interface will result from any process that induces collisions and sticking between the particles and the interfacial material. We consider here two forcing mechanisms related to the movement of water over the sediment bed (see Figure 5). For sufficiently large amplitude motions, particularly those associated with surface waves, the interfacial material may be set in motion and collisions between particles will result from shearing of the sediment bed itself. We have observed this mode of forcing of interfacial layers in several coastal embayments; others have described the interface as a "mobile carpet" [Summerhayes et al., 1985]. Alternatively, a flow over a motionless sediment bed may induce fluid motion within the porous interfacial material [Beavers and Joseph, 1967; Larsen and Higdon, 1987]. In this case, the collisions result from the advection of fine particles through the interfacial material which acts as a filter. Other forcing mechanisms such as spatially variable fluid pressure [Madsen, 1978; Harrison et al., 1983; Shum, 1992] are possible but are not considered here.

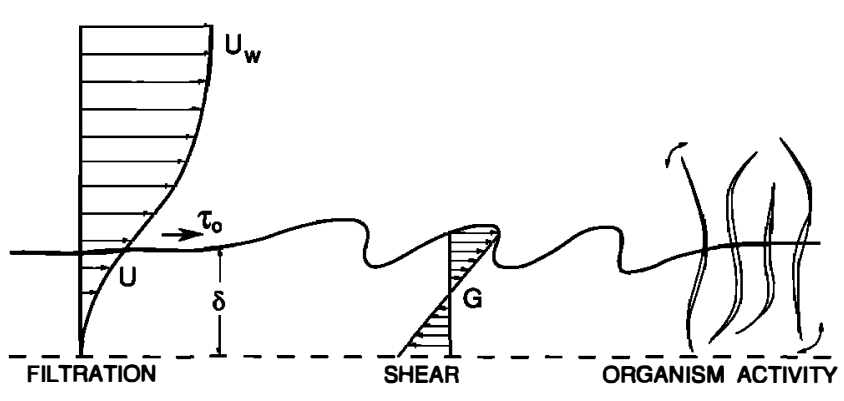

Fig. 5. Aggregation processes ai the sediment-water interface: à bottom boundary layer flow with velocity $U_{w}$ creates a bottom shear stress $\tau_{0}$ which induces an interfacial flow with velocity $U$; waves create a shearing of the interfacial material at a rate $G$ (reciprocal seconds). Either mechanism may result from organism activity.

We assume that, within an active interfacial layer of thickness $\delta$ (between $0.1 \mathrm{~cm}$ and $1.0 \mathrm{~cm}$ ) and solid fraction $\phi$ (between 0.01 and 0.1 , equivalent to a porosity between 0.90 and 0.99 ), the concentration of suspended fine particles is equal to $N_{p}$, the concentration in the water column immediately above the interface. This presumes that the same fluid motions producing the particle collisions keep the highly porous interfacial material well flushed by maintaining a circulation of fluid between the interfacial material and the water column. Our observations indicate that the interfacial shear induced by near-bottom wave motions is sufficiently vigorous to entrain overlying fluid. We hypothesize that the flushing of a motionless surface layer is maintained by unsteady bursts of vertical motion in the turbulent boundary layer that penetrate the porous interface [Robinson, 1991]. 
The rate of interfacial aggregation will depend upon the collision efficiency $\alpha$, defined as the fraction of potential collisions that actually occur and result in the particles sticling together. The value of the collision efficiency depends upon the particle surface chemistry, particularly surface charge, and upon the extent to which the parameterization of collision frequencies includes near-surface interactions between particles. In our theory we use relatively simple expressions for the frequency of collisions by interfacial shear and filtration for which the collision efficiency of natural particles has been found to range from $\alpha \simeq 10^{-3}$ to $\alpha=1$ [ $O^{\prime}$ Melia, 1987]. Typical values of $\alpha$ used in simulations of coagulation of marine particles are of the order of $\alpha=10^{-1}$ [e.g., Jackson, 1990].

Interfacial shear. If the interfacial material itself is in motion, particle collisions may be analyzed using coagulation theory [O'Melia, 1980]. Assuming that the suspended fine particles are much smaller than the interfacial flocs, the rate of fine particle aggregation per unit area is $\dot{N}_{\mathrm{I}}=\alpha G \phi \delta N_{\mathrm{p}} / \pi$, where $G$ is the rate of shearing (in reciprocal seconds). The effective deposition velocity defined by equation (1) is then given by

$$
V_{\mathrm{I}}=\alpha G \phi \delta / \pi
$$

Without a better understanding of the mechanical properties of interfacial layers it is difficult to relate the rate of shear to nearbottom water motions caused by waves or currents. However, during the field study at Salem Sound scuba divers observed an interfacial layer of thickness $\delta \simeq 1 \mathrm{~cm}$ being sheared by longwave swells. Assuming that the solids content of the active layer was about $\phi \simeq 0.1$ (typical of reported averages in the upper top centimeter), deposition of fine particles with $\alpha \simeq 5 \times 10^{-4}$ [Newman et al., 1990a] at a rate $V_{I} \simeq 0.26 \mathrm{~m}_{\text {day }}{ }^{-1}$ requires a shear rate $G \simeq 20 \mathrm{~s}^{-1}$. This magnitude of interfacial shear, equivalent to linear variation in velocity from zero to $20 \mathrm{~cm} \mathrm{~s}^{-1}$ over a distance of $1 \mathrm{~cm}$, is consistent with the observations of the layer movement by waves.

Interfacial filtration. When the sediment bed is motionless, particle aggregation may be analyzed using filtration theory [Spielman, 1977] for which the aggregation rate per unit area is $\dot{N}_{\mathrm{I}}=\alpha U \lambda \delta N_{\mathrm{p}}$, where $U$ is the velocity of the shear-induced flow within the interfacial layer, and $\lambda$ is the effective particle interception area per unit volume of interfacial material (sometimes called the filter coefficient). The effective deposition velocity is then

$$
V_{\mathrm{I}}=\alpha U \lambda \delta
$$

For a steady flow induced by a shear stress $\tau_{0}$, the magnitude of the shear-induced velocity $U$ and the thickness of the flow boundary layer $\delta$ may be estimated theoretically by considering a balance between the downward transfer of momentum by molecular viscosity and viscous drag on the interfacial matrix [Larsen and Higdon, 1987; Svensson and Rahm, 1991], resulting in

$$
U \simeq u_{*}^{2} \sqrt{\kappa} / \nu
$$

and

$$
\delta=\sqrt{\kappa}
$$

where $u_{\bullet}=\sqrt{\tau_{\mathrm{o}} / \rho_{\mathrm{f}}}$ is the shear velocity, $\kappa$ is the permeability of the interfacial material, and $\nu_{\mathrm{f}}=\mu_{\mathrm{f}} \rho_{\mathrm{f}}$ is the kinematic fluid viscosity. The effective deposition velocity is then

$$
V_{\mathrm{I}}=\alpha u_{*}^{2} \kappa \lambda \nu_{\mathrm{f}}
$$

Use of this relationship for $V_{I}$ requires additional assumptions about the structure of the interfacial material that lead to estimates of the permeability $\kappa$ and the filter coefficient $\lambda$. For simplicity we assume that the interfacial material is composed of uniformly distributed spherical elements of radius $R_{I}$ so that $\lambda=3 \phi / 4 R_{I}$ [Spielman, 1977]. Furthermore, the permeability of the interfacial material is assumed to be determined by the viscous (Stokes) drag on noninteracting spheres for which $\kappa=2 R_{\mathrm{I}}^{2} / 9 \phi$ [Happel and Brenner, 1983]. The resulting expression for the deposition velocity is

$$
V_{\mathrm{I}}=\alpha u_{*}^{2} R_{\mathrm{I}} / 6 v_{\mathrm{f}}
$$

This expression for $V_{I}$ is independent of the porosity of the interfacial material because the increase in collisions resulting from a higher density of interfacial material is balanced by decreases in the induced velocity and the depth of the active layer. Nearly the same result is obtained for other assumed elemental geometries such as cylinders [Masliyah et al., 1987] and, for the range of porosities of interest, it is little changed by consideration of flow interactions between interfacial elements [Happel and Brenner, 1983; Larsen and Higdon, 1987]. Stokenbach [1989] shows that equation (8) is also valid for an interfacial layer with a range of particle sizes, with $R_{\mathrm{I}}$ being the dimension of the smallest interfacial particles.

Aggregation by filtration in the interfacial layer depends upon the applied shear stress (or equivalently $u_{\bullet}$ ) and the interfacial particle size $R_{\mathrm{I}}$. The shear velocity is related to the velocity of the overlying water $U_{w}$ by $u_{*}{ }^{2}=C_{d} U_{w}{ }^{2}$, where $C_{d}$ is a friction coefficient of the order of $10^{-3}$ [Romar, 1976]. For water velocities varying from $U_{\mathrm{w}}=1 \mathrm{~cm} \mathrm{~s}^{-1}$ to $U_{\mathrm{w}}=10 \mathrm{~cm} \mathrm{~s}^{-1}$, the square of the shear velocity varies from $u_{*}^{2}=10^{-3} \mathrm{~cm}^{2} \mathrm{~s}^{-2}$ to $u_{*}^{2}=10^{-1} \mathrm{~cm}^{2} \mathrm{~s}^{-2}$. If the effective size of the flocs in the interfacial material is taken to range from $R_{\mathrm{I}}=10^{-2} \mathrm{~cm}$ to $R_{\mathrm{I}}=$ $10^{-1} \mathrm{~cm}$, the effective deposition velocity calculated from equation (8) ranges from $V_{I}=1.7 \times 10^{-7} \mathrm{~cm} \mathrm{~s}^{-1}$ to $V_{I}=$ $1.7 \times 10^{-1} \mathrm{~cm} \mathrm{~s}^{-1}$ or from about $10^{-4} \mathrm{~m} \mathrm{day}^{-1}$ to $100 \mathrm{~m} \mathrm{day}^{-1}$. For median parameter values $\left(\alpha=0.1, u_{*}^{2}=10^{-2} \mathrm{~cm}^{2} \mathrm{~s}^{-2}, R_{\mathrm{I}}=\right.$ $5 \times 10^{-2} \mathrm{~cm}$ ) the deposition velocity is $V_{\mathrm{I}}=8.3 \times 10^{-4} \mathrm{~cm} \mathrm{~s}^{-1}$ or about $0.7 \mathrm{~m}^{-1} \mathrm{y}^{-1}$.

It is of interest to note that the theorelical depth of the active interfacial layer (equation (6)) ranges from $\delta=0.015 \mathrm{~cm}$ to $\delta=$ $0.47 \mathrm{~cm}$ with a median value of $\delta=0.1 \mathrm{~cm}$. Thus significant removal of particles by filtration can occur in a very thin layer at the sediment-water interface. This is an important theoretical result that is consistent with our assumptions about flushing of the interface by the overlying water. Likely mechanisms for fluid replacement on this scale include flow into and out of microtopographic features of the interface and turbulent fluctuations in the viscous sublayer. Microprobe measurements by Gunderson and Jorgensen [1990] provide clear evidence of the magnitude of surface features and of flow-induced fluctuations at comparable depths into the sediment. Intrusion of vigorous fluid motions into the porous interfacial layer ensures that the supply of fine particles to the interface is not limited by transport within the bottom boundary layer.

\section{Comparison With Other Deposition Mechanisms}

Both observations and theory support the hypothesis that aggregation at the sediment-water interface can remove fine particles from suspension at effective deposition rates of 0.1 to $1.0 \mathrm{~m} \mathrm{day}^{-1}$ for weakly coagulating particles and potentially 
greater than $1 \mathrm{~m} \mathrm{day}^{-1}$ for particles with higher collision efficiencies. In this section we consider deposition by other physical and biological processes for the purpose of identifying conditions where interfacial aggregation may be the dominant mode. Of particular interest is the size range of fine particles that may be most affected by this process.

Settling and Brownian motion of primary particles. McCave [1985b] compared deposition by settling and by Brownian motion in a turbulent boundary layer and concluded that settling should dominate for particles in the size range of interest. Both of these processes are strongly dependent on particle size. For natural aggregates ranging in size from $0.001 \mu \mathrm{m}$ to $1000 \mu \mathrm{m}$ the settling velocity varies from about $10^{-8} \mathrm{~m} \mathrm{day}^{-1}$ to more than $100 \mathrm{~m} \mathrm{day}^{-1}$ (see Table 3). Organic sewage flocs and cells have been observed to settle about an order of magnitude more slowly than typical natural aggregates, reflecting their smaller relative density [Smayda, 1970; Wang, 1988]. Deposition by Brownian motion in a turbulent boundary layer increases as particle size decreases [O'Melia, 1980], but the effective deposition velocity is only about $0.3 \mathrm{~m} \mathrm{day}^{-1}$ for a $0.001-\mu \mathrm{m}$ particle in a boundary layer with a moderately high shear velocity of $u_{\bullet}=1 \mathrm{~cm} \mathrm{~s}^{-1}$ (see Table 3).

We conclude that deposition of particles smaller than $1 \mu \mathrm{m}$ by interfacial aggregation can easily exceed that resulting from either settling or Brownian motion, neither of which deposits particles

TABLE 3. Effective Deposition Velocity by Settling and Brownian Motion

\begin{tabular}{ccc}
\hline $\begin{array}{c}\text { Particle } \\
\text { Diameter, } \\
\mu \mathrm{m}\end{array}$ & $\begin{array}{c}\text { Settling } \\
\text { Velocity*, } \\
\text { m day }^{-1}\end{array}$ & $\begin{array}{c}\text { Effective } \\
\text { Velocity of } \\
\text { Deposition by } \\
\text { Brownian } \\
\text { Motiont, } \\
\text { m day }^{-1}\end{array}$ \\
\hline 0.001 & $3.1 \times 10^{-8}$ & 0.30 \\
0.01 & $3.1 \times 10^{-6}$ & 0.065 \\
0.1 & $3.1 \times 10^{-4}$ & 0.014 \\
1.0 & 0.031 & 0.0030 \\
10.0 & 1.2 & $6.5 \times 10^{-4}$ \\
100.0 & 24 & $1.4 \times 10^{-4}$ \\
1000.0 & 120 & $3.0 \times 10^{-5}$ \\
\hline
\end{tabular}

*Settling velocities from McCave [1984]. $\dagger$ Brownian deposition calculated using $u_{*}=$ $1.0 \mathrm{~cm} \mathrm{~s}^{-1}$ and absolute temperature $T_{\text {abs }}=$ 300K [O'Melia, 1980]. in this size range faster than about $0.1 \mathrm{~m}^{-1 a y^{-1}}$. Particles larger than about $10 \mu \mathrm{m}$ settle faster than about $1 \mathrm{~m} \mathrm{day}^{-1}$ and thus may be relatively unaffected by interfacial aggregation for many conditions.

Coagulation in the water column. The effective rate at which fine particles are removed from the water column by settling to the bottom will be increased if fine particles coagulate in the water column to form larger, faster-settling aggregates [McCave, 1984; Fowler and Knauer, 1986]. Farley and Morel [1986] have developed semiempirical expressions for unsteady mass removal from a well-mixed water column considering combined coagulation by the physical processes of Brownian motion, turbulent shear, and differential settling. We have used their expressions to compute the effective deposition velocity for several combinations of particle and water column parameters (see Table 4). Because the coagulation process determines the rate at which fast-settling particles are formed, the calculated deposition rate is effectively independent of the assumed initial size distribution of particles. Also, because the rate of particle mass removal given by Farley and Morel is only weakly dependent on water depth, the deposition velocity actually increases slightly with increasing water depth.

From these calculations (Table 4) we conclude that for the range of water depths considered here (up to $100 \mathrm{~m}$ ), deposition by interfacial aggregation may exceed that resulting from coagulation in the water column if the total suspended particle concentration is less than about $10 \mathrm{ppm}$. Coagulation in the water column will dominate in highly turbid environments such as estuaries [Edzwald et al., 1979] or following episodic resuspension events.

Feeding by organisms. Fine particles may be removed from suspension quite efficiently by the feeding activities of organisms in the water column and in the sediments. McCave [1984] notes that measured clearance rates for some zooplankton are equivalent to complete removal of all suspended particles in times as short as hours. This corresponds to $V_{I}=100 \mathrm{~m}^{-1}$ day $^{-1}$ for a $10-\mathrm{m}$-deep water body and $V_{I}=1000 \mathrm{~m} \mathrm{day}^{-1}$ for a depth of $100 \mathrm{~m}$. Filter feeding by the benthic suspension feeder Mytilus edulis was measured to be about $100 \mathrm{~L} \mathrm{~min}^{-1} \mathrm{~m}^{-2}$, which is equivalent to an effective deposition velocity of about $V_{\mathrm{I}}=100 \mathrm{~m}_{\text {day }}{ }^{-1}$ [Frechette et al., 1989].

Repackaging of particles is known to be an important process in geochemical cycling in aquatic systems, particularly those doep enough that interfacial processes are not significant [e.g. Gliwicz, 1986]. However, the importance of biological aggregation of fine particles is limited by two considerations. First, organism activity

TABLE 4. Effective Deposition Velocity Resulting From Coagulation-Mediated Settling

\begin{tabular}{cccccccc}
\hline & \multicolumn{5}{c}{ Collision Efficiency } \\
\cline { 2 - 4 } $\begin{array}{c}\text { Suspended Solids } \\
\text { Concentration, } \\
\text { ppm. }\end{array}$ & \multicolumn{3}{c}{ Water Depth $H=10 \mathrm{~m}$} & & \multicolumn{3}{c}{ Water Depth $H=100 \mathrm{~m}$} \\
\cline { 2 - 5 } \cline { 6 - 8 } \cline { 5 - 8 } & $\alpha=10^{-3}$ & $\alpha=10^{-1}$ & $\alpha=1.0$ & & $\alpha=10^{-3}$ & $\alpha=10^{-1}$ & $\alpha=1.0$ \\
\hline 0.01 & 0.0060 & 0.039 & 0.10 & & 0.015 & 0.10 & 0.32 \\
0.1 & 0.012 & 0.0850 & 0.30 & & 0.031 & 0.27 & 1.9 \\
1.0 & 0.025 & 0.26 & 2.0 & & 0.066 & 1.8 & 28 \\
10 & 0.059 & 1.9 & 29 & & 0.20 & 27 & 530 \\
100 & 0.22 & 27 & 520 & & 1.6 & 500 & 10,000 \\
\hline
\end{tabular}

All values are in meters per day. Effective deposition velocity is calculated as $V_{I}=$ $-H / c \mathrm{~d} c / \mathrm{d} t$, where $\mathrm{d} c / \mathrm{d} t$ is the decrease in suspended particle concentration given by Farley and Morel [1986]: fluid shear $G=\left(\epsilon / v_{\mathrm{f}}\right)^{1 / 2}$ where $\nu_{\mathrm{f}}$ is fluid linematic viscosity $\left(=10^{-2} \mathrm{~cm} \mathrm{~s}^{-1}\right.$ for water) and $\epsilon$ is dissipation rate $\left(=C_{\mathrm{D}} U_{\mathrm{w}}{ }^{3} / H\right.$ where $C_{\mathrm{D}}$ is the friction coefficient $\left(=10^{-3}\right)$ and $U_{\mathrm{w}}$ is water velocity $\left(=10 \mathrm{~cm} \mathrm{~s}^{-1}\right)$ ); normalized particle density difference is $\left(\rho_{\mathrm{p}}-\rho_{\rho}\right) / \rho_{\mathrm{f}}=0.1$; absolute temperature $\mathrm{T}_{\mathrm{abs}}=300 \mathrm{~K}$. 
is temporally and spatially variable; there are many imes and places where the population densities are insufficient to be a factor in particle removal. Second, organisms are known to be selective in the range of sizes removed by feeding, and few organisms are efficient in filtering particles smaller than $1 \mu \mathrm{m}$ [Gerritsen and Porter, 1982]. However, as is shown by our experiments, organisms may contribute indirectly to interfacial aggregation by agitating the sediments and by altering the sediment properties that affect aggregation such as porosity, floc size, and collision efficiency.

\section{ConClusions}

Evidence from laboratory experiments, field measurements, and theory supports our hypothesis that fine particles are removed from suspension by aggregation in a porous and mobile layer at the sediment-water interface driven by the near-bottom water motion or by the activities of benthic organisms. The rate of aggregation is determined by the intensity of the physical or biological forcing and by other physiochemical properties of the layer such as its thickness, particle size distribution, and particle collision efficiency.

Aggregation rates measured in our experiments were equivalent to deposition velocities on the order of 0.1 to $1.0 \mathrm{~m} \mathrm{day}^{-1}$ for model fine particles with a relatively low collision efficiency. Extrapolation of these measurements to more typical collision efficiencies indicates that particles in natural water bodies may be deposited by this process at effective rates of 1 to $10 \mathrm{~m} \mathrm{day}^{-1}$ or greater. Of particular significance is the aggregation of extremely fine submicron particles observed in the field study at Salem Sound. For this size particle, and even for slower-settling particles as large as $10 \mu \mathrm{m}$, interfacial aggregation may be the dominant mode of deposition, exceeding settling, scavenging by large particles, or ingestion by organisms.

We conclude that interfacial aggregation is potentially a majo1 factor in geophysical and geochemical processes involving fine particles. Clearly, much more work is needed to better identify and quantify the mechanisms of this process and its influence on local and large-scale particle transport.

Acknowledgments. Thanks to M. Bothner, P. Gschwend, F. M. M. Morel and A. M. Teeter for helpful conversations. This work was supported by EPA grant CR-81181-01-01, by the MTT Sea Grant College Program, under NOAA Grant NA86AA-D-SG089, and by a postgraduate scholarship awarded to the second author by the Natural Sciences and Engineering Research Council of Canada.

\section{REFERENCES}

Archer, D., S. Emerson, and C. R. Smith, Direct measurement of the diffusive sublayer at the deepsea floor using oxygen microelectrodes, Nature, 340, 623-626, 1989.

Baker, J. E., S. J. Eisenreich, and B. J. Eadie, Sediment trap fluxes and benthic recycling of organic carbon, polycyclic aromatic hydrocarbons, and polychlorobiphenyl congeners in Lake Superior, Environ. Sci. Technol., 25, 500-509, 1991.

Beavers, G. S., and D. J. Joseph, Boundary conditions at a naturally permeable wall, J. Fluid. Mech., 30, 197-207, 1967.

Beier, J. A., S. G. Wakeham, C. H. Pilskaln, and S. Honjo, Ennichment in saturated compounds of Black Sea interfacial sediment, Nature, 351, 642-644, 1991.

Billett, D. S. M., R. S. Lampitt, A. L. Rice, and R. F. C. Mantoura, Seasonal sedimentation of phytoplankton to the deep-sea benthos, Nature, 302, 520-522, 1983.

Bothner, M. H., and P. C. Valentine, A new instrument for sampling flocculent material at the water/sediment interface, J. Sediment. Petrol., 52, 39-640, 1982.

Butman, C. A., W. D. Grant, and K. D. Stolzenbach, Predictions of sediment trap biases in turbulent flows: A theoretical analysis based on observations from the literature. J. Mar. Res., 44, 601-44, 1986.

Clegg, S. L., and M. Whitfield, A generalized model for the scavenging of trace metals in the open ocean, I, Particle cycling, Deep Sea Res., 37, 809-832, 1990.

Davison, W., G. W. Grime, J. A. W. Morgan, and K. Clarke, Distribution of dissolved iron in sediment pore waters at aubmillimeter resolution, Nature, 352, 323-325, 1991.

Edzwald, J. K., J. B. Upchurch, and C. R. O'Melia, Coagulation in estuaries, Environ. Sci. Technol., 8, 58-63, 1979.

Farley, K. J., and F. M. M. Morel, The role of coagulation in the kinetics of sedimentation, Environ. Sci. Technol., 20, 187-195, 1986.

Fisher, J. B., W. J. Lick, P. L. McCall, and J. A. Robbins, Vertical mixing of lake sediments by tubificid oligochaetes, J. Geophys. Res., 85, 3997-4006, 1980.

Fitzgerald, M. G., Anthropogenic influence of the sedimentary regime of an urban estuary: Boston Harbor, Tech. Rep. WHOI-80-38, Woods Hole Oceanogr. Inst., Woods Hole, Mass., 1980.

Fowler, S. W., and G. A. Knauer, Role of large particles in the transport of elements and organic compounds through the oceanic water column, Prog. Oceanogr., 16, 147-194, 1986.

Frechette, M., C. A. Butman, and W. R. Geyer, The importance of boundary-layerflow processes in supplying phytoplanktonto the benthic suspensionfeeder, Mytilus edulis, Limnol. Oceanogr., 34, 19-36, 1989.

Gerritsen, J., and K. G. Porter, The role of surface chemistry in filter feeding by zooplankton, Science, 216, 1225-1227, 1982.

Gliwicz, M. Z., Suspended clay concentration controlled by filter foeding zooplankton in a mopical reservoir, Nature, 323, 330-332, 1986.

Gunderson, J. K., and B. B. Jørgensen, Microstructure of diffusive boundary layers and the oxygen uptake of the sea floor, Nature, 345, 604-607, 1990.

Happel, J., and H. Brenner, Low Reynolds Number Hydrodymamics, Martinus Nijhoff, The Hague, Netherlands, 1983.

Harrison, W. D., D. Musgrave, and W. S. Reeburgh, A wave-induced transport process in marine sediments, J. Geophys. Res., 88, 7617-7622, 1983.

Hecker, B., Photographic evidence for the rapid flux of particles to the sea floor and their transport down the continental shelf, Deep Sea Res., 37, 1773-1782, 1990.

Hunt, T. R., and J. D. Pandya, Sewage sludge coagulation and settling in seawater, Environ. Sci. Technol., 18, 119-121, 1984.

Jackson, G. A., A model of the formation of marine algal flocs by physical and coagulation processes, Deep Sea Res., 37, 1197-1211, 1990.

Jahnke, R. A., S. R. Emerson, J. K. Cochran, and D. J. Hirschberg, Fine scale distributions of porosity and particulate excess ${ }^{210} \mathrm{~Pb}$, organic carbon and $\mathrm{CaCO}_{3}$ in surface sediments of the deep equatorial Pacific, Earth Planet. Sci. Letr., 77, 59-69, 1986.

Komar, P. D., Boundary layer flow under steady unidirectional currents, in Marine Sediment Transport and Environmental Management, edited by D. J. Stanley and D. J. P. Swift, pp. 91-106, John Wiley, New York, 1976.

Lal, D., and A. Lerman, Size spectra of biogenic particles in ocean water and sediments, J. Geophys. Res., 80, 423-430, 1975.

Lampitt, R. S., Evidence for the seasonal deposition of detritus to the deep-sea floor and its subsequent resuspension, Deep Sea Res., 32, 885-897, 1985.

Larsen, R. E., and J. J. L. Higdon, Microscopic flow near the surface of two-dimensional porous media, Part 2, Transverse flow, J. Fluid Mech., 178, 119-136, 1987.

Lee, C., J. W. Farrington, and R. B. Gagosian, Sterol geochemistry of sediments from the North Atlantic Ocean and adjacent coastal areas, Geochim. Cosmochim. Acta, 43, 35-46, 1979.

Madsen, O. S., Wave-induced pore pressures and effective stresses in a porous bed, Geotechnique, 28, 377, 1978.

Masliyah, J. H., G. Neale, K. Malysa, and T. G. M. Van de Ven, Creeping flow over a composite sphere: Solid core with porous shell, Chem. Eng. Sci., 42, 245-253, 1987.

McCave, I. N., Vertical flux of particles in the ocean, Deep Sea Res., 22, 491-502, 1975.

McCave, I., Size-spectra and aggregation of suspended particles in the deep ocean, Deep Sea Res., 31, 329-352, 1984.

McCave, I. N., Erosion, transport, and deposition of fine-grained marine sediments, in Fine-Grained Sediments: Deep Water Processes and Facies, edited by A. V. Snow, pp. 35-61, Blackwell Scientific, Boston, Mass., 1985a. 
McCave, I. N., Mechanics of deposition of fine-grained sediments frum nephloid layers, Geo Mar. Lett., 4, 243-245, 1985b.

Newman, K. A., F. M. M. Morel, and K. D. Stolzenbach, Settling and coagulation characteristics of fluorescent particles determined by flow cytometry and fluorometry, Environ. Sci. Technol., 24, 506-513, $1990 a$.

Newman, K. A., S. L. Frankel, and K. D. Stolzenbach, Flow cytomeric detection and sizing of fluorescent particles deposited at a sewage outfall site, Environ. Sci. Technol., 24, 513-519, 1990 .

Olivarez, A. M., R. M. Owen, and D. T. Long, Geochemistry of rare earth elements in benthic layer particulate matter and sediments of Lake Superior, J. Great Lakes Res., 15, 59-67, 1989.

O'Melia, C. R., Aquasols: The behavior of small particles in aquatic systems, Environ. Sct. Technol., 14, 1052-1060, 1980.

O'Melia, C. R., Particle-particle interactions, in Aquatic Surface Chemistry: Chemical Processes at the Particle-Water Inserface, edited by W. Stumm, pp. 385-404, John Wiley, New York, 1987.

Payatakes, A. C., and L. Gradon, Dendritic deposition of aerosol particles in fibrous media by inertial impaction and interception, Chem. Eng. Sci., 35, 1083-1096, 1980.

Reimers, C. B., An in situ microprofiling instrument for interfacial pore water gradients: Methods and oxygen profiles from the North Pacific Ocean, Deep Sea Res., 34, 2019-2035, 1987.

Rhoads, D. C., and L. F. Boyer, The effect of marine benthos on physical properties of sediments: A successional perspective, in Animal-Sediment Relations, edited by P. L. McC̈all and M. J. S. Tevesz, pp. 3-52, Plenum, New York, 1982.

Rhoads, D. C., and S. Cande, Sediment profile camera for in-situ study of organism-sedimentrelations, Limnol. Oceanogr., 16, 110-114,1971.

Rhoads, D. C., L. F. Boyer, B. K. Welsh, and G. R. Hampson, Seasonal dynamics of detritus in the benthic turbidity zone (BTZ); Implications for bottom-rack molluscan mariculture, Bull. Mar. Sci., 35, 536-549, 1984.

Robinson, S. K., Coherent motions in the turbulent boundary layer, Ann. Rev. Fluid Mech., 23, 601-639, 1991.

Ross, M. A., a nd A. J. Mehta, On the mechanics of histoclines a nd fluid mud, J. Coastal Res., SI5, 51-61, 1989.

Santschi, P. H., D. M. Adler, and M. Amdurev, The fate of particles and particle-reactive trace metals in coastal waters: Radioisotope studies in microcosms, in Trece Metals in Seawater, NATO Conf. Ser., vol. edited by C. S. Wong, E. Boyle, K. W. Bruland, and J. D. Burton, pp. 331-349, Plenum, New York, 1983.

Shum, K. T., Wave-induced advective transport below a rippled watersediment interface, J. Geophys. Res., 97, 789-808, 1992.

Smayda, T. J., Normal and accelerated sinking of phytoplankton in the sea, Mar. Geol., 11, 105-22, 1970.

Spielman, L. A., Paricle capture from low speed laminar flows, Annu. Rev. Fluid Mech., 9, 297-19, 1977.

Stolzenbach, K. D., Particle transport and attachment, in Structure and Function of Biofilms, edited by W. G. Characklis and P. A. Wilderer, pp. 33-47, John Wiley, New York, 1989.

Summerhayes, C. P., J. P. Ellis, and P. Stoffers, Estuaries as sinks for sediment and industrial waste: A case history from the Massachusetts cosst, Contrib. Sedimentol., 14, pp. 1-47, 1985.

Svensson, U., and L. Rahm, Toward a mathematical model of oxygen transfer to and within bottom sediments, J. Geophys. Res., 96, 2777-2783, 1991.

Wakeham, S. G., Algal and bacterial hydrocarbons in particulate matter and interfacial sediment of the Cariaco Trench, Geochim. Cosmochim. Acra, 54, 1325-1336, 1990.

Wang, R.-F. T., Laboratory analysis of settling velocities of wastewater particles in seawater using holography, EQL Rep. No. 27, Environ. Qual. Lab., Calif. Inst. of Technol., Pasadena, 1988.

Williams, D. J. A., and P. R. Williams, Rheology of concentrated cohesive sediments, J. Coastal Res., SI5, 165-173, 1989.

Witten, T. A., and M. B. Cates, Tenuous structures from disorderly growth processes, Science, 232, 1607-1612, 1986.

K. A. Newman, 141 Ayer Road, Harvard, MA 01451.

K. D. Stolzenbach, Civil Engineering Department, University of California, Los Angeles, CA 900241593.

C. S. Wong, Department of Civil and Mineral Engineering, University of Minnesota, Minneapolis, MN 55455.

Received May 31, 1991; accepted July 17, 1992.) 